13

\title{
Нанокомпозиционный оптосенсор ионов свинца в воде
}

\author{
( И.Ю. Денисюк, Ю.А. Игнатьева, М.В. Успенская, М.И. Фокина \\ Университет ИТМО, \\ 197101 Санкт-Петербург, Россия \\ e-mail: denisiuk@mail.ifmo.ru
}

Поступила в редакцию 16.01.2019 г.

В окончательной редакции 16.01.2019 г.

Принята к публикации 23.01.2019 г.

\begin{abstract}
Исследованы спектральные зависимости комплексообразования в системе краситель ксиленовый оранжевый, иммобилизованный на поверхности наночастиц $\mathrm{ZnO}$, введенных в объем гидрогеля, и ионы свинца $\mathrm{Pb}^{2+}$. Показано, что осаждение красителя на наночастицы ZnO приводит к связыванию его на поверхности и отсутствию вымывания из гидрогеля, однако этот процесс не препятствует образованию комплексов красителя с ионами свинца, что характеризуется повышением поглощения в области $580 \mathrm{~nm}$. В связи с высокой чувствительностью пленочного нанокомпозита к присутствию малых концентраций свинца он может быть использован в качестве сенсора.
\end{abstract}

DOI: $10.21883 /$ OS.2019.06.47768.28-19

Одним из актуальных вопросов современности является экспресс-мониторинг загрязнений окружающей среды соединениями тяжелых металлов, поступающих в водные бассейны как из отходов горно-обогатительных комбинатов и нефтегазовых скважин, так и в результате разработки карьеров открытым способом [1]. Имеется несколько альтернативных физических и химических процессов, обеспечивающих эту задачу, но оптимальный способ в настоящее время не определен. Наиболее токсичными являются ионы тяжелых металлов, такие как $\mathrm{Hg}^{2+}$ и $\mathrm{Pb}^{2+}$. Это хорошо известные биоаккумулятивные, небиоразлагаемые и высокотоксичные загрязнения окружающей среды, представляющие высокий риск для здоровья человека. Накопление ионов тяжелых металлов и их превращение в органические соединения в организме человека через пищевую цепь могут иметь серьезные последствия для здоровья, такие как повреждение головного мозга, почечная недостаточность и различные когнитивные и двигательные расстройства [2]. Поэтому исключительно актуально создание новых систем и датчиков, пригодных для экспресс-анализа в полевых условиях и имеющих высокую точность и чувствительность.

Современные методы обнаружения этих ионов включают атомно-абсорбционную спектрометрию, рентгеновскую флуоресцентную спектроскопию и индуктивносвязанную плазмо-масс-спектрометрию (ICP-MS). Хотя методы лабораторного анализа могут давать сверхчувствительные аналитические результаты, они обычно требуют дорогостоящего оборудования, сложных и длительных методов измерения и высокого уровня навыков оператора и выполняются только в специализированной лаборатории, не являясь экспресс-диагностикой.

Один из принципов детектирования тяжелых металлов основан на образовании комплексов красителя с ионами тяжелых металлов, при этом тяжелый металл определяется по изменению спектральных свойств красителя. Данный принцип положен в основу лаборатор- ных методов определения тяжелых металлов, базирующихся на титровании растворов, а также используется в желатиновых пленках, в которых иммобилизированный краситель изменяет окраску при образовании комплекса с металлом [3]. Однако работа с растворами требует лабораторного оборудования, а иммобилизация в органической желатиновой пленке не позволяет получить стабильные и воспроизводимые результаты, краситель не удерживается в геле и быстро вымывается. Использование полимерной матрицы ограничено степенью гидрофильности и проницаемости для ионов свинца.

Новым направлением создания сенсоров тяжелых металлов являются оптические сенсоры, основанные на образовании комплексов ионов тяжелого металла с красителем, введенным в гидрофильную матрицу полимера. C учетом возможности накопления измеряемых ионов в объеме гидрогеля, чувствительность метода может достигать $10^{-6} \mathrm{M} / 1$, что позволяет в перспективе создавать высокочувствительные малогабаритные сенсоры для экспресс-диагностики загрязнений питьевой воды на уровне ниже предельно допустимой концентрации [4]. Образование комплексов красителя ксиленовый оранжевый с ионами ряда металлов в водных растворах хорошо известно и используется, в частности, для определения содержания микроколичеств методом титрования [5]. В данной работе проведено создание и исследование нанокомпозита, чувствительный элемент которого краситель ксиленовый оранжевый - иммобилизован на поверхности наночастиц, сшитых с полимерной гидрофильной матрицей, пленки из которой получены фотополимеризацией.

\section{Условия и методы эксперимента}

В работе использовалась фотополимеризующаяся матрица на базе смеси акриловых мономеров и во- 
дорастворимого полимера. В качестве водорастворимого полимера использовался полиэтиленгликоль Poly(ethylene glycol) (PEG, Aldrich № 94646), молекулы которого были иммобилизованы в сетке фотополимеризованного акрилата. Использованные акрилаты Trimethylolpropane ethoxylate $(1 \mathrm{EO} / \mathrm{OH})$ methyl ether diacrylate (TMP, Aldrich № 415871) и 2-Carboxyethyl acrylate (2-Car Aldrich № 552348) с одной стороны обеспечивают формирование пространственной сетки, с другой - имеют функциональные кислотные группы. Соотношение компонентов композиции по весу составляло 2-Car:TMP:PEG $=64: 7: 29$. Инициатор УФ полимеризации 2,2-диметокси-2-фенилацентофенон (Aldrich 19,611-8) в концентрации 0.1 wt.\%. Основные принципы получения фотополимеризующегося гидрогеля описаны в работе [6].

Приготовление композиции проводилось следующим образом: после смешивания мономеров в состав добавлялся PEG в виде гранул и производилось его растворение в смеси мономеров при воздействии ультразвука с плотностью мощности $70 \mathrm{~W} / \mathrm{cm}^{2}$. По окончании процесса образовывался вязкий прозрачный раствор, готовый к фотополимеризации.

В качестве чувствительного вещества использовался краситель ксиленовый оранжевый, осажденный на наночастицы $\mathrm{ZnO}$. Концентрация наночастиц в итоговой композиции составляла 3 wt.\%, концентрация красителя 0.35 wt.\%. Наночастицы $\mathrm{ZnO}$ активировались прокаливанием при температуре $400^{\circ} \mathrm{C}$ в течение $1 \mathrm{~h}$, далее они помещались в безводный изопропанол, в который при ультразвуковом диспергировании вводился по каплям раствор ксиленового оранжевого в воде. При этом краситель, не растворимый в изопропаноле, адсорбировался на наночастицах. Наночастицы с адсорбированным красителем сушились при температуре $70^{\circ} \mathrm{C}$ и вводились в мономерную композицию при интенсивном ультразвуковом воздействии. Образовывался темно-красный, вязкий нанокомпозит, содержащий краситель, адсорбированный на поверхности наночастиц, введенных в фотополимеризуемую гидрофильную матрицу.

Пленки нанокомпозита были изготовлены методом фотополимеризации с последующей термообработкой в соответствии с процедурой, описанной в работе [7]. Они представляли собой свободные пленки толщиной порядка 300 мкм, что оптимально для использования их в качестве сенсора. Для исключения воздействия на эксперимент остаточных мономеров время экспонирования было увеличено в 5 раз относительно времени полной полимеризации, а готовые образцы подвергались термообработке при $50^{\circ} \mathrm{C}$ в течение одних суток. Полученные образцы гидрогеля представляли собой мягкую, прозрачную пленку, способную к поглощению воды до трех исходных объемов при сохранении оптической прозрачности. Для удобства исследования методами оптической спектроскопии пленки наносили на подложку из стекла методом полива жидкой композиции с последующей фотополимеризацией.

\section{Экспериментальные результаты и их обсуждение}

Динамика поглощения воды полученной матрицей приведена на рис. 1. Наблюдаемая величина водопоглощения 200\% достаточна для получения однородной, прозрачной гелеобразной мембраны [6], обеспечивающей фиксацию чувствительного элемента сенсора наночастиц, покрытых ксиленовым оранжевым, и в то же время проницаемость для ионов свинца, подлежащих определению.

Адсорбция ксиленового оранжевого на поверхность наночастиц, введенных в гидрогель, обеспечивает его стабилизацию и отсутствие вымывания при погружении в воду. При этом наблюдается сдвиг максимума спектра красителя в красную область, что указывает на наличие взаимодействия красителя с поверхностью наночастиц (рис. 2, кривые 3 и 4). При введении спектра красителя непосредственно в гидрогель он легко вымывается (рис. 2, кривые 1 и 2). Наблюдаемый сдвиг максимума

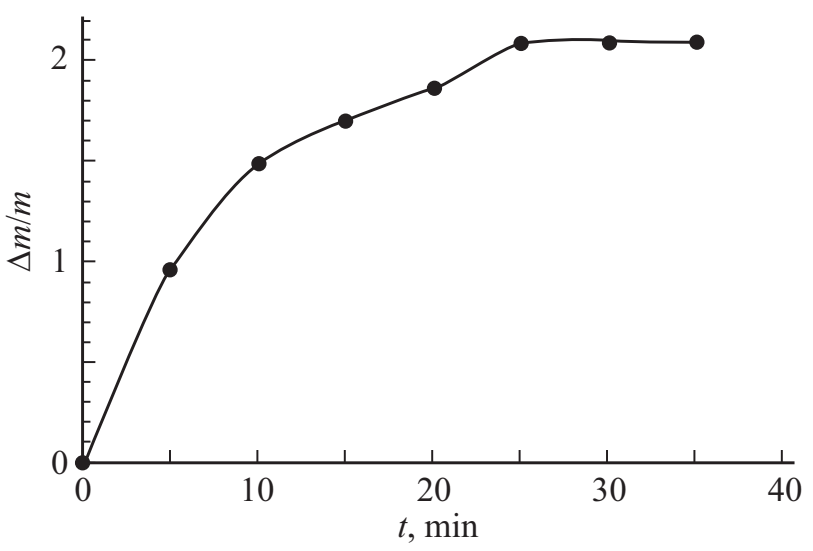

Pис. 1. Динамика поглощения воды пленкой гидрогеля: приращение массы при выдержке в воде.

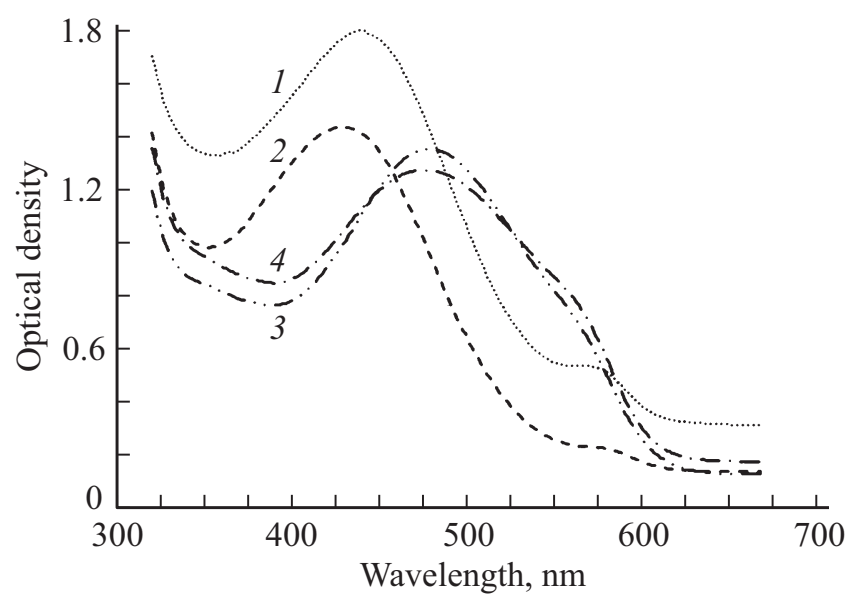

Рис. 2. Спектры поглощения ксиленового оранжевого $(1,2)$ и комплексов $\mathrm{ZnO}$ - ксиленовый оранжевый $(3,4)$ в полимерной матрице до $(1,3)$ и после $(2,4)$ выдержки в воде в течение $30 \mathrm{~h}$. 


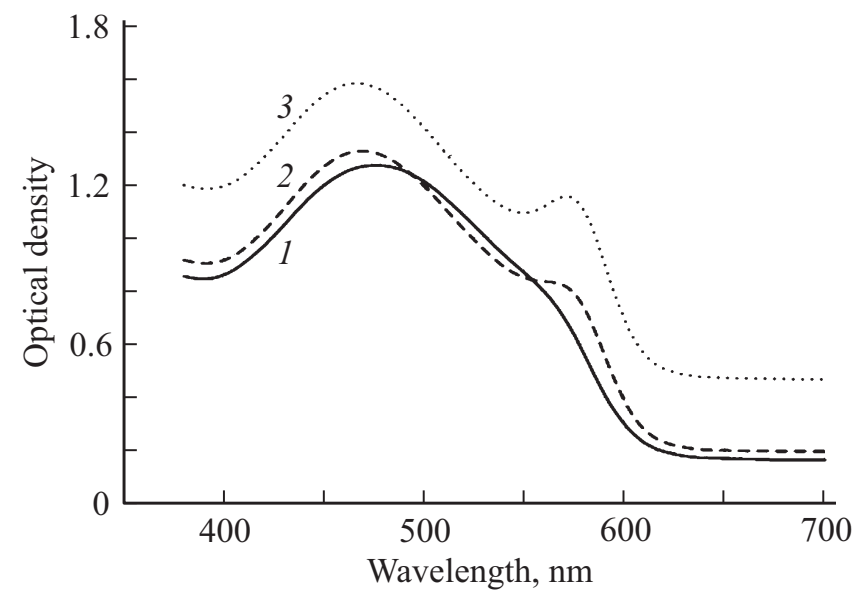

Pис. 3. Спектр поглощения композита после $10 \mathrm{~min}$ в водном растворе с содержанием ионов свинца: 0 (1), 0.002 (2), $0.006 \%(3)$.

красителя при его адсорбции на поверхность наночастиц весьма значителен и свидетельствует о наличии химического взаимодействия между ними (рис. 2, кривые 1 и 3), однако данный максимум не соответствует комплексу ксиленовый оранжевый - цинк $580 \mathrm{~nm}$ [5]. Вероятно, сдвиг основного максимума поглощения является результатом взаимодействия наночастицы с ОН-группами молекул красителя с получением агрегированного состояния ксиленового оранжевого, не растворимого в воде.

Измерение чувствительности к ионам свинца проводилось путем погружения пленки гидрогеля с красителем в водный раствор ацетата свинца заданной концентрации на 10 min и последующим контролем изменения спектра поглощения. Концентрация ионов свинца в измеряемом растворе составляла 20-60 mg/l. Исходная толщина полимерных пленок составляла порядка $300 \mu \mathrm{m}$.

При погружении пленки в раствор ионов свинца происходит образование комплекса ксиленовый оранжевыйсвинец, что приводит к появлению нового максимума в области $580 \mathrm{~nm}$, амплитуда которого пропорциональна концентрации ионов свинца в растворе (рис. 3) и может быть использована в качестве параметра для создания приборов мониторинга микроколичеств ионов свинца, основанных на пропускании воды через сенсорную гидрогелевую мембрану.

Предельно допустимая концентрация ионов свинца в водоеме составляет по ГОСТ-287473 - $0.1 \mathrm{mg} / \mathrm{l}$, причем в реках, на берегах которых находятся горнообогатительные комбинаты, концентрация свинца достигает $2-10 \mathrm{mg} / 1$ [1]. Пороговая чувствительность исследуемого материала составляет приблизительно $2 \mathrm{mg} / 1$, что показывает его пригодность для мониторинга содержания свинца в водоемах, подверженных загрязнениям отходами горно-обогатительных предприятий с целью оперативного определения источников их поступления в водную среду, путем отслеживания показаний навстречу течению. Поскольку чувствительным элементом являет- ся гидрогелевая пленка, содержащая иммобилизованный краситель, повышение чувствительности к ионам свинца возможно при фильтрации воды через нее и накоплению адсорбируемого металла.

\section{Выводы}

Проведено исследование пленочного оптосентора на основе системы ксиленового оранжевого, адсорбированного на наночастицах $\mathrm{ZnO}$ в фотополимеризуемой гидрофильной матрице. Показано, что краситель, адсорбированный на поверхности наночастиц, не вымывается при нахождении пленки в воде, его спектр сдвигается в красную область относительно водного раствора, а образование его комплексов с ионами свинца происходит так же, как в растворе, с появлением максимума при $580 \mathrm{~nm}$, соответствующего образующемуся комплексу, амплитуда которого пропорциональна концентрации ионов свинца в воде. Порог чувствительности, измеренный в нашей работе, составил $2 \mathrm{mg} / \mathrm{l}$, а диапазон линейности в координатах - концентрация ионов свинца: амплитуда максимума при $580 \mathrm{~nm}$ - до $60 \mathrm{mg} / \mathrm{l}$.

Прозрачность нанокомпозита, высокая его чувствительность к ионам свинца, линейность зависимости оптического поглощения от концентрации ионов свинца в воде, возможность получения пленок любой толщины и формы методом фотополимеризации, позволяет рассматривать данный нанокомпозиционный материал как чувствительный элемент оптосенсора ионов свинца, пригодный для экспресс-мониторинга загрязнений воды в водоемах.

\section{Конфликт интересов}

Авторы заявляют, что у них нет конфликта интересов.

\section{Список литературы}

[1] Иикова С.В., Троч Н.М., Горшкова О.В. // Изв. Самарского научного центра РАН. 2012. Т. 14. № 5. С. 217-222.

[2] Ye B.F., Zhao Y.J., Cheng Y., Li T.T., Xie Z.Y., Zhao X.W., Gu Z.Z. // Nanoscale. 2012. V. 4. N 19. P. 5998-6003.

[3] Кулешова Н.В., Савина Л.А. // Вестн. Нижегородского ун-та им. Н.И. Лобачевского. Сер. Химия. 2004. № 1. С. 219-224.

[4] Yang Y.K., Yook K.J., Tae J. // J. Am. Chem. Soc. 2005. V. 127. N 48. P. $16760-16761$.

[5] Belleza O.J.V., Villaraza A.J.L. // Inorgan. Chem. Commun. 2014. V. 47. P. 87-92.

[6] Kim B.K., Paik S.H. // J. Polymer Science. Part A: Polymer Chemistry. 1999. V. 37. N 15. P. 2703-2709.

[7] Smirnova T.V., Burunkova Y.E., Denisyuk I.Y. // J. Optical Technology. 2006. V. 73. N 5. P. 352-355. 